\title{
Synthesis and Characterization of 5-Fluorouracil-Loaded Glutaraldehyde Crosslinked Chitosan Hydrogels
}

\author{
Zehra ÖZBAŞ⿻1,2, Gülten GÜRDAĞ ${ }^{1}$ \\ ${ }^{1}$ İstanbul Üniversitesi, Mühendislik Fakültesi, Kimya Mühendisliği Bölümü, 34320, İstanbul \\ ${ }^{2}$ Çankırı Karatekin Üniversitesi, Mühendislik Fakültesi, Kimya Mühendisliği Bölümü, 18100, Çankırı
}

(Alınış / Received: 07.06.2016, Kabul / Accepted: 03.11.2016, Online Yayınlanma / Published Online: 18.11.2016)

\section{Keywords \\ Chitosan, \\ Crosslinking, \\ Drug delivery, \\ 5-Fluorouracil}

\begin{abstract}
In this work, the characterization and drug release behavior of 5fluorouracil-loaded glutaraldehyde-crosslinked chitosan hydrogels have been studied. The structure of the hydrogels were investigated by Fourier transform infrared spectroscopy, differential scanning calorimetry, and X-ray diffraction, also their properties were compared with those of the drug-unloaded hydrogels. The equilibrium swelling studies and drug release profiles were determined at $37^{\circ} \mathrm{C}$ in two different pHs (2.1 and 7.4). The results indicated that increased chitosan concentration in the hydrogel decreased the swelling and drug release values and the hydrogels released nearly the same amount of 5-fluorouracil in both acidic $(\sim 59 \%)$ and basic medium $(\sim 50 \%)$.
\end{abstract}

\section{5-Florourasil Yüklü Glutaraldehit ile Çapraz Bağlanmış Kitosan Hidrojellerin Sentezi ve Karakterizasyonu}

\section{Anahtar Kelimeler}

Kitosan,

Capraz bağlanma,

İlaç salımı,

5-Florourasil

\begin{abstract}
Özet: Bu çalışmada, 5-florourasil yüklü glutaraldehit ile çapraz bağlanmış kitosan hidrojellerinin karakterizasyonu ve ilaç salım davranıșı incelenmiștir. Hidrojellerin yapısı Fourier transform infrared spektroskopisi, diferansiyel taramalı kalorimetre ve X-ışını kırınımı ile aydınlatılmıştır, ayrıca bu hidrojellerin yapıları ilaç yüklü olmayan hidrojeller ile karşılaştırılmıştır. Denge şişme çalışmaları ve ilaç salım profilleri $37^{\circ} \mathrm{C}^{\prime} \mathrm{de}$ ve iki farkl $\mathrm{pH}$ 'ta (2.1 ve 7.4$)$ tespit edilmiștir. Sonuçlar, hidrojelde artan kitosan konsantrasyonunun şişmeyi ve ilaç salım miktarını azalttığını göstermiştir ve hidrojelin asidik $(\sim 59 \%)$ ve bazik $(\sim 50 \%)$ ortamda neredeyse aynı miktarda 5-florourasil salımı yaptığı görülmüştür.
\end{abstract}

\section{Introduction}

Hydrogels are hydrophilic, three-dimensional and polymeric networks that can absorb large amount of water or biological fluids $[1,2]$. Their resemblance to living tissue makes them suitable for medical applications [3,4]. Especially, the natural polymer, chitosan (CS) is a good candidate because of the stimuli responsive property [5].

CS is a deacetylated form of the natural biopolymer chitin and it is a linear polysaccharide consisting of Dglucosamine and $\mathrm{N}$-acetyl-D-glucosamine units [6]. CS can be chemically modified through highly reactive hydroxyl and amino groups [7].

CS, as a polycationic polymer with pKa around 6.5 , shows high solubility in acidic solutions with $\mathrm{pHs}$ below pKa because of the protonation of its free amino groups, while the amino groups in the medium with $\mathrm{pHs}$ above $\mathrm{pKa}$ are deprotonated and it becomes insoluble $[8,9]$. Degree of deacetylation (DD, the ratio of $\mathrm{N}$-acetyl-D-glucosamine to D-glucosamine structural units) (75-95\%) and molecular weight (MW) (50-2000 kDa) are the two main characteristic parameters influencing its properties [10]. Those parameters can be adjusted according to the source and preparation procedure of chitosan. In addition, its biodegradability, antibacterial activity, nontoxicity and biocompatibility properties make CS useful in different applications such as medical, pharmaceutical and environmental applications $[11,12]$.

CS hydrogels can be classified as chemical and physical hydrogels, and covalently crosslinked hydrogels are named chemical hydrogels, while physical hydrogels are formed by ionic interactions 
[11]. Glutaraldehyde (GA) and epiclorohydrin (ECH) can be used as chemical crosslinkers and [13-15], anions and anionic molecules can also be used for ionic crosslinking of CS [16-18]. Amongst the crosslinkers for CS, glutaraldehyde (GA) which is a bifunctional and water soluble crosslinker, is highly efficient and economical [19]. The crosslinking reaction of GA with CS occurs through Schiff base reaction via covalent bond imine bond $-\mathrm{C}=\mathrm{N}-$ formation between the amine groups of CS and the aldehyde group of GA [20], and the reaction is accompanied by color formation $[21,22]$. The color of GA-crosslinked CS hydrogel varies from white to redbrick and after drying the hydrogel, it turns to yellow to dark red-brick [23].

5-fluorouracil (5-FU) is an anticancer drug for the treating solid tumors in clinical chemotherapy [2426] and it is an acidic and hydrophilic drug [27]. This drug is a good candidate for minimizing the adverse effects by controlled release technology [28].

Bhat et al. developed 5-FU-loaded and GA-crosslinked CS microspheres by emulsification method using a gelatin capsule. CS microspheres showed higher release in acidic medium than basic medium, whereas the capsule device showed higher release in basic medium which is a potential for targeted delivery to the colon [29]. Mirzaei et al. prepared freeze-dried and GA-crosslinked CS hydrogels containing amoxicillin antibiotic. The hydrogels had higher swelling at the lowest pH and the hydrogels with 20 mol\% crosslinker showed the best swelling for drug release [30]. Chitosan microparticles were prepared in the presence of the drug, clozapine, through sieving techniques by Agnihotri and Aminabhavi [31]. The clozapine release rates of these particles increased with decreasing GA amount due to the nontightly crosslinked matrices which cause faster diffusion of the drug at pH 7.4. Wet spinning method was used to synthesize implantable 5-fluorouracilloaded chitosan scaffolds by Denkbaş et al. and the drug loading amount was found between 0.21-7.55 mg drug per g of CS. Drug release properties were done in phosphate buffer solution. Initially the drug release was fast, but it was constant at the later time period, and they concluded that the system was quite suitable for long-term applications [32]. Kulkarni et al prepared GA-crosslinked CS beads for the release of diclofenac sodium [33]. The release medium was acidic for the first $3 \mathrm{~h}$, then it was changed to $\mathrm{pH} 7.4$. The drug release rate was low for the beads prepared at high temperatures compared to those at low temperatures under the same conditions, and the diffusion rate of the drug decreased by the crosslinking of polymer [33]. Wang et al. [34] synthesized magnetic GA-crosslinked CS-5-FU nanoparticles for a targeting drug carrier system, and the release rate of 5 -FU was $68 \%$ in $30 \mathrm{~h}$ at $\mathrm{pH} 7.2$. The strong hydrogen bonding between the drug and CS decreased the release rate from magnetic nanoparticles. Gupta and Kumar [35] compared the drug (diclofenac sodium) release behavior of GAcrosslinked CS beads and microgranules. The release rate of drug was slower for beads compare to microgranules. The drug release percentages were found to be higher in acidic medium due to the high swelling of the matrix in acidic $\mathrm{pH}$.

As reported in some studies, different crosslinking agents for CS except GA have been using in drug release studies. To prepare crosslinked chitosan film was used by Shu et al. [36]. At $\mathrm{pH}<3.5$, the film swelled, and brilliant blue and riboflavin were released completely within $120 \mathrm{~min}$, whereas the swelling rate was lower under neutral conditions and the drug release rate was lower than $40 \%$ in simulated intestinal fluid. They suggested that these films are suitable for stomach-specific drug delivery. Sulfate, citrate and TPP crosslinked chitosan beads were synthesized by Shu and Zhu [37]. The controlled drug (riboflavin) release was influenced by $\mathrm{pH}$ and ionic strength, which related to the nature of anions. The beads crosslinked by both tripolyphosphate and citrate (or sulfate) exhibited excellent pH-sensitivity. The drug release percentages were relatively high in simulated gastric fluid compared to those in simulated intestinal fluid, and they suggested those beads for the stomach- specific drug delivery. Hejazi and Amiji [38] developed a stomach-specific drug delivery system from chitosan microspheres for an anti-Helicobacter pylori agent in the stomach. They showed that tetracycline-loaded chitosan microspheres may be used effectively in the stomach against Helicobacter pylori.

In this work, 5-FU-loaded crosslinked CS hydrogels with different CS concentrations were prepared. The structure of the obtained hydrogels was investigated by FTIR (Fourier transform infrared) spectroscopy, DSC (Differential scanning calorimetry) and XRD (Xray diffraction). For the comparison, crosslinked CS hydrogels without 5-FU were characterized as well. The equilibrium swelling percentages of 5-FU-loaded hydrogels were determined at $\mathrm{pH} 2.1, \mathrm{pH} 7.4$, and distilled water, and their release characteristics for 5 FU were observed in pH 2.1 and 7.4 in this work.

\section{Material and Method}

\subsection{Material}

CS, GA (aqueous solution of 25 wt \%) and 5-FU were obtained from Sigma-Aldrich (St. Louis, MO). The flow times of different concentration of CS solutions (range $0.05-0.35 \mathrm{~g} / \mathrm{dL}$ ) were measured to find out the viscosity average molecular weight of CS, and the value was found to be $125.600 \mathrm{~g} \mathrm{~mol}^{-1}[5,39]$. The deacetylation degree of CS was determined by FTIR analysis from absorbance values attained from 1650 and $3450 \mathrm{~cm}^{-1}$ which are characteristic for amide I and hydroxyl bands, respectively. The value was found to be $77 \%[5,40]$. Glacial acetic acid (AAc) was of Riedel-de Haen (Seelze, Germany) product. All 
buffer chemicals were purchased from Merck Chemicals Ltd (Hohenbrunn, Germany).

\subsection{Synthesis of hydrogel}

CS solutions were prepared by dissolving a given amount of CS $(0.25$ and $0.5 \mathrm{~g})$ in $15 \mathrm{~mL}$ of aqueous acetic acid ( $2 \mathrm{v} / \mathrm{v} \%)$ with stirring using a magnetic stirrer. Then, $75 \mathrm{mg}$ of 5 -FU was added to the CS solution and it was stirred until the drug was completely dissolved. Upon dissolution, GA was diluted 1:4 with distilled water and added to the CS solution to obtain a 1:1 CS:GA ratio in mol. After obtaining a homogeneous mixture, it was casted in a petri dish and held there at room temperature until the gelation was completed. Then, the obtained hydrogels were cut into smaller cylindrical pieces, and they were washed with distilled water and dried in air and then vacuum-dried until constant weight. For comparison purpose, the hydrogels were also prepared without adding the drug 5-FU. Since at higher CS concentrations, a homogeneous CS solution could not be obtained, a higher concentration of CS than $>0.02 \mathrm{~g} / \mathrm{mL}$ was not used in this study. The feed composition of the hydrogels was given in Table 1. The polymers were prepared using two different amounts of CS, 0.25 and $0.5 \mathrm{~g}$, and it was presented in polymer codes as CS1 and CS2, respectively. In addition, the symbol $\mathrm{F}+$ and $\mathrm{F}$ - denoted the drugloaded and -unloaded polymer, respectively.

Tablo 1. The feed composition of the GA-crosslinked CS hydrogels with/without 5-FU.

\begin{tabular}{cccc}
$\begin{array}{c}\text { Polymer } \\
\text { Code }\end{array}$ & $\begin{array}{c}\text { CS concentration } \\
(\mathrm{g} / \mathrm{ml})\end{array}$ & $\begin{array}{c}\text { Mass } \\
\text { of GA } \\
(\mathrm{g})\end{array}$ & $\begin{array}{c}\text { Mass of } \\
5-\mathrm{FU} \\
(\mathrm{mg})\end{array}$ \\
\hline CS1:GA:F+ & 0.017 & 0.183 & 75 \\
CS2:GA:F+ & 0.033 & 0.366 & 75 \\
CS1:GA:F- & 0.017 & 0.183 & - \\
CS2:GA:F- & 0.033 & 0.366 & - \\
\hline
\end{tabular}

\subsection{Characterization}

FTIR spectra of the hydrogels and pure 5-FU were recorded on a Spectrum One (Perkin-Elmer, USA) spectrometer by potassium bromide pellet technique. The thermal properties of the hydrogels and 5-FU were determined using ca. 15 mg sample by DSC 131 (Setaram, France). The DSC was scanned between 50 and $350^{\circ} \mathrm{C}$, in a nitrogen atmosphere at heating rates of $10^{\circ} \mathrm{C} / \mathrm{min}$. XRD studies were done for pure 5 -FU hydrogels by using a DMAX-2200 x-ray diffractometer (Rigaku Company, Japan) with $\mathrm{Cu}-\mathrm{K \alpha}$ tube at $30 \mathrm{~mA}$ and $40 \mathrm{kV}$.

The swelling experiments were performed at distilled water, $\mathrm{pH} 2.1$ ( $\mathrm{HCl}-\mathrm{KCl})$, and $\mathrm{pH} 7.4\left(\mathrm{KH}_{2} \mathrm{PO}_{4}{ }^{-}\right.$ $\mathrm{Na}_{2} \mathrm{HPO}_{4}$ ). According to the table given by Perrin and Dempsey, the buffer solutions were prepared [41]. The dry hydrogels were immersed in those mediums at $37^{\circ} \mathrm{C}$ for 24 hours long, and at intervals, they were removed from the swelling medium until the equilibrium was reached. The equilibrium swelling percentage $\left(\mathrm{S}_{\mathrm{eq}} \%\right)$ was determined from the equation (1):

$$
S_{e q}(\%)=\left(W_{s}-W_{d}\right) / W_{d} * 100
$$

where $W_{s}$ is the weight of the swollen hydrogel at equilibrium, and $\mathrm{W}_{\mathrm{d}}$ is the weight of dry hydrogel. The buffer solutions were adjusted to ionic strength of $0.09 \mathrm{M}$ with sodium chloride.

\subsection{Drug loading and release studies}

The entrapped drug amount in the hydrogels was calculated by the determination of 5-FU in the washing water by UV spectrophotometer $\left(\lambda_{\max }=266\right.$ $\mathrm{nm})$. The difference in drug amount between the initial employed and the washing water was used as the amount of loaded drug [5]. 5-FU content of washing water was determined by using the calibration curve of 5-FU dissolved in distilled water. The drug loading capacity (mg drug/g polymer) was determined from the equation (2):

$$
\text { Loading capacity }=\frac{M_{i d}-M_{r d}}{M_{p}}
$$

where $M_{i d}$ is the initial amount of drug, $M_{r d}$ is the residual amount of drug and $M_{p}$ is the amount of polymer.

In vitro release studies of 5 -FU were done under $\mathrm{pH}$ of 2.1 and 7.4 at $37^{\circ} \mathrm{C}$. At various intervals, the buffer solution (aliquot) was removed and replaced with equal volume of fresh buffer. The amount of drug was estimated spectrophotometrically at $266 \mathrm{~nm}$ (PerkinElmer Lambda 35 UV-VIS Spectrophotometer). Drug release amount was estimated from the calibration curve of 5-FU dissolved in $\mathrm{pH} 2.1$ and 7.4. All the measurements were done in triplicate, and the average values were considered for calculation. Cumulative drug release (\%) was determined from the equation (3):

$$
\text { Cumulative release, } \%=\left[\frac{\left(V_{o} C_{n}+V_{e} \sum_{1}^{n-1} C_{i}\right)}{m}\right] * 100 \text {, }
$$

where $V_{o}$ is the volume of release medium $(10 \mathrm{ml}), V_{e}$ is the volume of release media taken out every time $(3 \mathrm{ml}), \mathrm{C}_{\mathrm{i}}$ is the concentration of 5 -FU released from gel at intervals of $\mathrm{i}, \mathrm{m}$ is the mass of 5-FU loading, and $\mathrm{n}$ is the replacement times.

\section{Results and Discussion}

As can be seen in Figure 1, the hydrogels are in white and red-brick color with increasing CS concentration (Figure 1a), while they turned from yellow to dark red-brick after drying (Figure 1b). In addition, although the drug was completely dissolved during the hydrogel preparation, the drug crystals were observed after drying. 


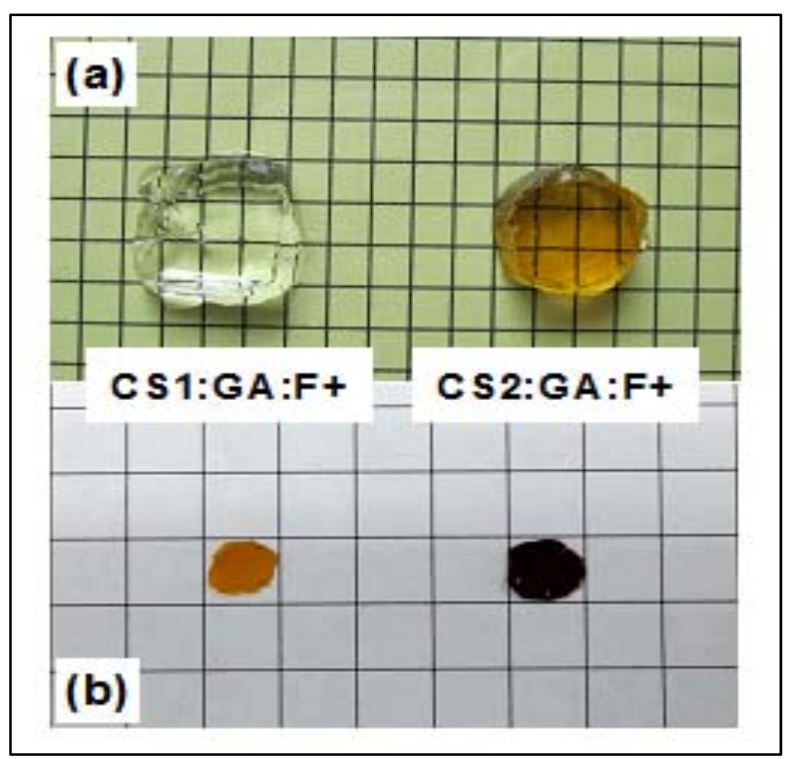

Figure 1. Optical appearances of the hydrogels before (a) and after (b) drying

The FTIR spectrum of CS in acetic acid (chitosonium acetate, $\mathrm{CS}^{-\mathrm{NH}_{3}}{ }^{+} \mathrm{COO}-{ }^{-}[3,42,43]$ is given in Figure $2 \mathrm{a}$. Carbonyl stretching vibrations (at 1728 and $1657 \mathrm{~cm}^{-}$ ${ }^{1}$ ) in the ester bond are characteristic for chitosonium acetate [8]. The broad band appeared at $3363 \mathrm{~cm}^{-1}$ is originated from $\mathrm{O}-\mathrm{H}$ and $\mathrm{N}-\mathrm{H}$ group stretching in chitosonium acetate, and the overlapped band presents the intermolecular hydrogen bonds between chitosonium acetate chains $[8,44]$. The saccharide structure was observed at $1150 \mathrm{~cm}^{-1}$, and the strong band from $\mathrm{C}-0$ stretching vibration in $\mathrm{CS}$ was observed at $1070 \mathrm{~cm}^{-1}[8,45]$. In comparison to the FTIR spectra of chitosonium acetate, there are two main changes in the spectra of crosslinked CS hydrogels (CS1:GA:F- and CS2:GA:F-)(Figure 2a). The first one is the presence of the sharp band at 1654 $\mathrm{cm}^{-1}$ due to the stretching vibration of the imine $(\mathrm{C}=\mathrm{N})$ bond confirming the reaction between $-\mathrm{NH}_{2}$ groups of CS and -CHO groups of GA [29]. The second one is the band at $1568 \mathrm{~cm}^{-1}$ was shifted to higher wavenumbers with the decrease in intensity in the spectrum of crosslinked CS. After the crosslinking reaction, as expected, the decrease in the primary amine groups caused a decrease in the intensity of the N-H band.

The FTIR spectra of 5-FU and 5-FU-loaded crosslinked CS hydrogels (CS1:GA:F+ and CS2:GA:F+) are given in Figure 2b. The main bands for 5-FU are assigned as follows: $1242 \mathrm{~cm}^{-1}$ (C-F stretching bands), $1655 \mathrm{~cm}^{-1}$ (C=0 stretching vibration), and $3067 \mathrm{~cm}^{-1}$ (N-H stretching vibration) $[10,46]$. The spectra of drug-loaded and unloaded hydrogels not showed big differences except the band around $1247 \mathrm{~cm}^{-1}$ in the spectrum of CS1:GA:F+ and CS2:GA:F+ (Figure 2b) which shows the presence of the drug $[5,46]$ and this finding proves any strong chemical interactions between the drug and polymer.

Figure 3 shows the DSC curves of pure 5-FU, 5-FUloaded (CS1:GA:F+) and 5-FU-unloaded (CS1:GA:F-) hydrogels. As seen from the DSC thermogram of pure
5 -FU, the endothermic peak at $285^{\circ} \mathrm{C}$ indicates the melting temperature of the drug. However, this characteristic peak is not seen in the drug-loaded hydrogel, which indicates that the drug may have been molecularly dispersed in the hydrogel matrix or converted into amorphous form during heating [47]. In addition, the exothermic peak around $250-260^{\circ} \mathrm{C}$ in DSC curve of CS1:GA:F- and CS1:GA:F+ can be attributed to the decomposition of crosslinked chitosan $[48,49]$.

To examine the crystallinity of 5-FU in the hydrogels, XRD studies have been performed. Figure 4 shows the XRD diffraction patterns of pure 5-FU and, 5-FUloaded (CS2:GA:F+) and 5-FU-unloaded (CS2:GA:F-) hydrogels. The crystalline nature of pure $5-\mathrm{FU}$ is confirmed by the intensive peaks at $2 \theta$ of $16^{\circ}, 29^{\circ}$ and $31^{\circ}$. The drug crystals which formed after drying were observed at $2 \theta$ of $29^{\circ}$ with a considerably weak intensity in the drug-loaded hydrogel which means that there is no any interaction between the polymer and the drug [47].

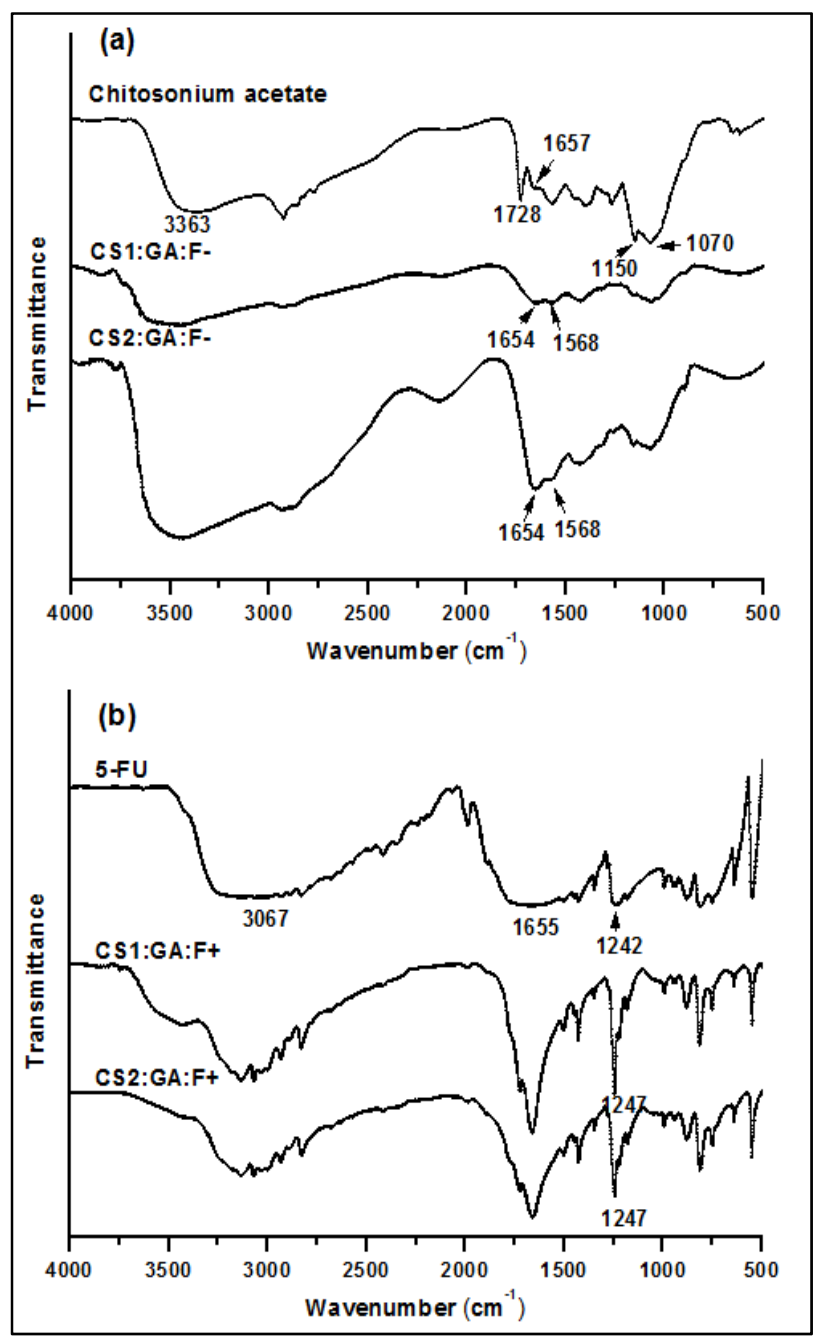

Figure 2. (a) FTIR spectra of chitosonium acetate, CS1:GA:F- and CS2:GA:F-, (b) FTIR spectra of 5-FU, CS1:GA:F+ and CS2:GA:F+

The equilibrium swelling values of drug-loaded crosslinked CS in distilled water, pH's 2.1 and 7.4 are given in Figure 5. As seen in Figure 5, at pH 2.1 the 
crosslinked CS hydrogels exhibited more swelling than at $\mathrm{pH}$ 7.4. In acidic solutions, CS has a positive charge consisting of the protonated amino groups: $\mathrm{NH}_{3}+$ leading to the creation of the repulsion forces between the same charged polymer chains allowing the diffusion of water into the hydrogel. On the other hand, with the increase in $\mathrm{pH}$ from 2.1 to 7.4 , the protonation degree of amino groups decreases and repulsion forces between the polymer chains disappears. It is due to the reason that the swelling capacities of crosslinked CS hydrogels decrease with the increase in $\mathrm{pH}$. In distilled water (at $\mathrm{pH} \sim 6.5$ ), since the degree of protonation of CS is very low, the $\mathrm{S}_{\text {eq }} \%$ values are lower than that in acidic medium.

Molar ratios of CS/GA in CS1 and CS2 gels are the same. Namely, in CS1 gel, 0.25 g CS was dissolved in $15 \mathrm{~mL} 2 \mathrm{v} / \mathrm{v} \%$ aqueous acetic acid solution and GA was used in the twice of molar amount of - $\mathrm{NH} 2$ groups in $0.25 \mathrm{~g}$ CS. In CS2 gel, $0.5 \mathrm{~g}$ CS was dissolved in $15 \mathrm{~mL} 2 \mathrm{v} / \mathrm{v} \%$ aqueous acetic acid solution and GA amount in mole was twice that of -NH2 groups in 0.5 g CS. So, molar ratio of CS/GA in both gel and the theoretical crosslinking density are the same. Thus, the equilibrium swelling values given in Figure 5 confirms that the crosslink densities of CS1:GA:F+ ve CS2:GA:F+ gels are the same. On the other hand, the difference between the two gels is that CS and GA concentrations in solution in case 2 are two times more concentrated that those of case 1 .

The increased CS concentration led to decrease in the drug loading capacity of the hydrogels as given 62.4 and $16.0 \mathrm{mg}$ drug/g polymer for CS1:GA:F+ and CS2:GA:F+ hydrogels, respectively. As given in the literature, GA crosslinked CS network has a fast gelation rate [50], most probably, the increase in the CS and GA concentration caused a fast solidification of the hydrogel, and this situation prevents the movement of the drug around the polymer chain to entrap 5-FU into the network [51]. As a result, the drug loading capacity decreased with the increase in GA content.

The pH-dependent 5-FU release trend of the hydrogels in $\mathrm{pH} 2.1$ and $\mathrm{pH} 7.4$ was given as a function of time at $37^{\circ} \mathrm{C}$ in Figure 6 . As seen in the figure, the 5-FU release percentages from the hydrogels at $\mathrm{pH} 2.1$ are higher than those at $\mathrm{pH} 7.4$. At $\mathrm{pH} 2.1$, the protonation of the amino groups of CS led to high swelling and accordingly high drug release (58.8\% and $14.3 \%$ for CS1:GA:F+ and CS2:GA:F+, respectively), whereas, at $\mathrm{pH} 7.4$, the low swelling value led to low drug release percentage (50.1\% and $8.6 \%$ for CS1:GA:F+ and CS2:GA:F+, respectively). As expected, the release rate increased in the case of high drug loading. In addition, the release percentages of 5-FU of the hydrogels with high CS content are lower and slower than those with low CS content in both buffer solutions.

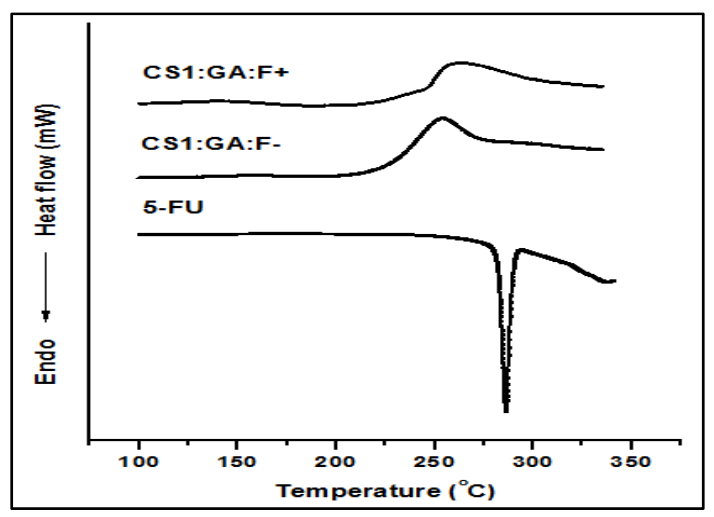

Figure 3. The DSC curves of 5-FU, CS1:GA:F- and CS1:GA:F+

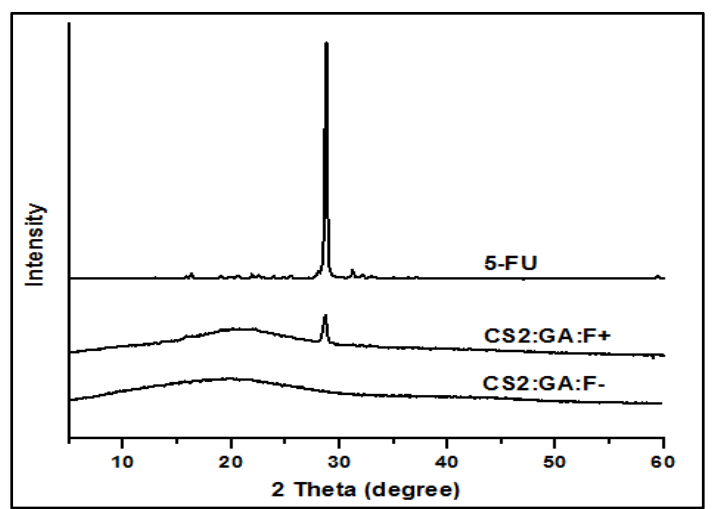

Figure 4. XRD pattern of pure 5-FU, CS2:GA:F- and CS2:GA:F+

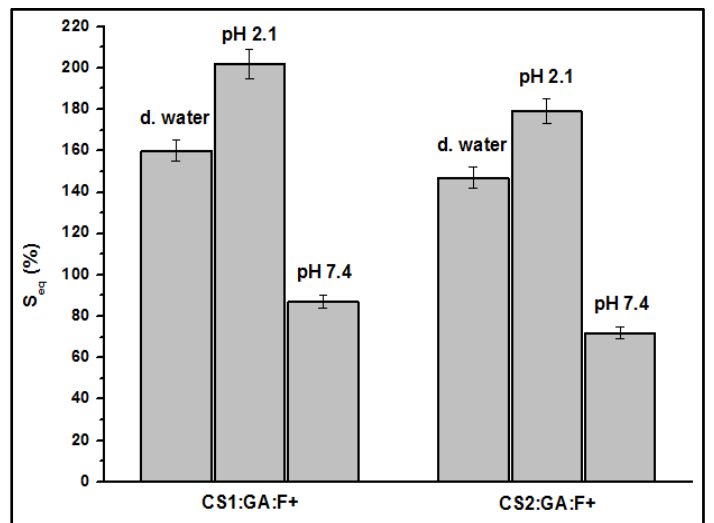

Figure 5. $\mathrm{S}_{\mathrm{eq}} \%$ values of 5 -FU-loaded hydrogels in different media at $37^{\circ} \mathrm{C}$

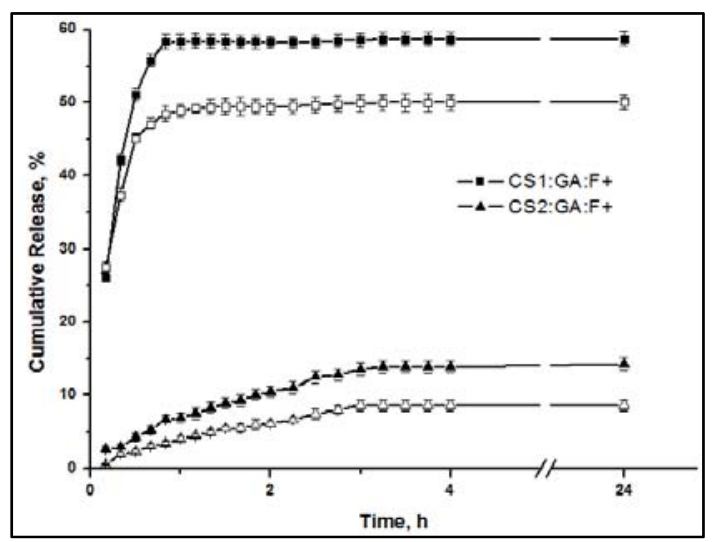

Figure 6. Drug release trend of the hydrogels at $\mathrm{pH}$ 2.1 (closed symbol) and pH 7.4 (open symbol) 


\section{Conclusion}

5-FU-loaded GA-crosslinked CS hydrogels were synthesized and characterized by FTIR, DSC and XRD analyses. The absence of chemical interactions between the drug and polymer was confirmed by FTIR, XRD and DSC analysis. The hydrogels showed maximum swelling and high cumulative drug releases at $\mathrm{pH}$ 2.1. Higher drug loading in the hydrogel showed higher release percentages of the drug. The hydrogel with high CS content had a slower and lower drug release rate compared to the hydrogel with low CS content. The findings of this study showed that GA-crosslinked CS hydrogel can be used in the stomach specific drug delivery applications.

\section{Acknowledgement}

This work was supported by the Research Fund of Istanbul University, Project No: 11970.

\section{References}

[1] Pulat, M., Asıl, D. 2009. Fluconazole Release Through Semi-Interpenetrating Polymer Network Hydrogels Based on Chitosan, Acrylic Acid, and Citraconic Acid. Journal of Applied Polymer Science, 113, 2613-2619.

[2] Pulat, M., Akalın, G. O., Karahan, N. D. 2014. Lipase Release Through Semi-Interpenetrating Polymer Network Hydrogels Based on Chitosan, Acrylamide, and Citraconic Acid. Artificial Cells, Nanomedicine and Biotechnology, 42, 121-127.

[3] Mansur, H. S., Orefice, R. L., Mansur, A. A. P. 2004. Characterization of Poly(Vinyl Alcohol)/Poly(Ethylene Glycol) Hydrogels and PVA-derived Hybrids by Small-Angle X-ray Scattering and FTIR Spectroscopy. Polymer, 45 (21), 7193-7202.

[4] Peppas, N. A., Bures, P., Leobandung, W., Ichikawa, H. 2000. Hydrogels in Pharmaceutical Formulations. European Journal of Pharmaceutics and Biopharmaceutics, 50 (1), 27-46.

[5] Özbaş Z., Gürdağ G. 2015. Swelling Kinetics, Mechanical Properties, and Release Characteristics of Chitosan-Based Semi-IPN Hydrogels. Journal of Applied Polymer Science, 132 (16), 41886.

[6] Bhattarai, N., Gunn, J., Zhang, M. 2010. ChitosanBased Hydrogels for Controlled, Localized Drug Delivery. Advanced Drug Delivery Reviews, 62 (1), 83-99.

[7] Dutta, P. K., Dutta, J., Tripathi, V. S. 2004. Chitin and Chitosan: Chemistry, Properties and Applications. Journal of Scientific and Industrial Research, 63, 20-31.
[8] Sarmad, S., Yenici, G., Gürkan, K., Keçeli, G., Gürdağ, G. 2013. Electric Field Responsive Chitosan-Poly (N, N-dimethyl acrylamide) SemiIPN Gel Films and Their Dielectric, Thermal and Swelling Characterization. Smart Materials and Structures, 22 (5), 055010.

[9] Wu, L. Q., Gadre, A. P., Yi, H., Kastantin, M. J., Rubloff, G. W., Bentley, W. E., Payne, G. F., Ghodssi, R. 2002. Voltage-Dependent Assembly of The Polysaccharide Chitosan onto An Electrode Surface. Langmuir, 18 (22), 86208625.

[10] Raafat, D., Sahl, H. G. 2009. Chitosan and Its Antimicrobial Potential-A Critical Literature Survey. Microbial Biotechnology, 2 (2), 186-201.

[11] Berger, J., Reist, M., Mayer, J. M., Felt, O., Peppas, N. A., Gurny, R. 2004. Structure and Interactions in Covalently and Ionically Crosslinked Chitosan Hydrogels for Biomedical Applications. European Journal of Pharmaceutics and Biopharmaceutics, 57 (1), 19-34.

[12] Baroni, P., Vieira, R. S., Meneghetti, E., Silva, M. G. C., Beppu, M.M. 2008. Evaluation of Batch Adsorption of Chromium Ions on Natural and Crosslinked Chitosan Membranes. Journal of Hazardous Materials, 152 (3), 1155-1163.

[13] Vieira, R. S., Beppu, M.M. 2006. Interaction of Natural and Crosslinked Chitosan Membranes with Hg (II) Ions. Colloid Surface A, 279, 196207.

[14] Wan Ngah, W. S., Endud, C. S., Mayanar, R. 2002. Removal of Copper (II) Ions from Aqueous Solution onto Chitosan and Cross-linked Chitosan Beads. Reactive and Functional Polymers, 50 (2), 181-190.

[15] Chen, A. H., Liu, S. C., Chen, C. Y., Chen, C. Y. 2008. Comparative Adsorption of $\mathrm{Cu}$ (II), $\mathrm{Zn}$ (II), and $\mathrm{Pb}$ (II) Ions in Aqueous Solution on The Crosslinked Chitosan with Epichlorohydrin. Journal of Hazardous Materials, 154 (1-3), 184191.

[16] Brack, H. P., Tirmizi, S. A., Risen, W.M. 1997. A Spectroscopic and Viscometric Study of The Metal Ion-Induced Gelation of The Biopolymer Chitosan. Polymer, 38 (10), 2351-2362.

[17] Du, W. L., Niu, S. S., Xu, Y. L., Xu, Z. R., Fan, C. L. 2009. Antibacterial Activity of Chitosan Tripolyphosphate Nanoparticles Loaded with Various Metal Ions. Carbohydrate Polymers, 75 (3), 385-389.

[18] Zhao, Q. S., Ji, Q. X., Xing, K., Li, X. Y., Liu, C. S., Chen, X. G. 2009. Preparation and Characteristics of Novel Porous Hydrogel Films Based on Chitosan and Glycerophosphate. Carbohydrate Polymers, 76 (3), 410-416. 
[19] Wu, X., Black, L., Santacana-Laffitte, G., Patrick, C. W. 2007. Preparation and Assessment of Glutaraldehyde-Crosslinked Collagen-Chitosan Hydrogels for Adipose Tissue Engineering. Journal of Biomedical Materials Research, 81A (1), 59-65.

[20] Zhang, J., Zhou, X., Wang, D., Wang, Y., Zhou, X., Wang, H., Li, Q., Tan, S. 2013. Studies on The Coimmobilized GOD/CAT on Cross-linked Chitosan Microsphere Modified by Lysine. Journal of Molecular Catalysis B-Enzymatic, 97, 80-86.

[21] Roberts, G. A. F., Taylor, K. E. 1989. Macromolecular Chemistry and Physics, 190 (5), 951-960.

[22] Argüelles-Monal, W., Goycoolea, F. M., Peniche, C., Higuera-Ciapara, I. 1998. Rheological Study of The Chitosan/Glutaraldehyde Chemical Gel System. Polymer Gels and Networks, 6 (6), 429440.

[23] Monteiro Jr, O. A. C., Airoldi, C. 1999. Some Studies of Crosslinking Chitosan-Glutaraldehyde Interaction in A Homogeneous System. International Journal of Biological Macromolecules, 26 (2-3), 119-128.

[24] Mundargi, R. C., Rangaswamy, V., Aminabhavi, T. M. 2010. A Novel Method to Prepare 5fluorouracil, An Anti-Cancer Drug, Loaded Microspheres from Poly (N-vinyl caprolactamco-acrylamide) and Controlled Release Studies. Designed Monomers and Polymers, 13 (4), 325336.

[25] Babu, V. R., Sairam, M., Hosamani, K. M., Aminabhavi, T. M. 2006. Preparation and Invitro Release of Chlorothiazide Novel pHSensitive Chitosan-N, N'-dimethylacrylamide Semi-Interpenetrating Network Microspheres. International Journal of Pharmaceutics, 325 (12), 55-62.

[26] Sekhar, E. C., Krishna Rao, K. S. V., Raju, R. R. 2011. Chitosan/Guargum-g-Acrylamide Semi IPN Microspheres for Controlled Release Studies of 5-Fluorouracil. Journal of Applied Pharmaceutical Science, 01 (08), 199-204.

[27] Ermis, D., Yuksel, A. 1999. Preparation of spraydried microspheres of indomethacin and examination of the effects of coating on dissolution rates. Journal of Microencapsulation, 16 (3), 315-324.

[28] Krishna Rao, K. S. V., Chung, I., Reddy, K. M., Ha, C. S. 2009. PMMA-Based Microgels for Controlled Release of An Anticancer Drug. Journal of Applied Polymer Science, 111 (2), 845-853.

[29] Bhat, S. K., Keshavayya, J., Kulkarni, V. H., Reddy, V. K. R., Kulkarni, P. V., Kulkarni, A.R. 2012. Preparation and Characterization of Crosslinked
Chitosan Microspheres for The Colonic Delivery of 5-fluorouracil. Journal of Applied Polymer Science, 125 (3), 1736-1744.

[30] Mirzaei, B. E., Ramazani, S. A. A., Shafiee, M., Danaei, M. 2013. Studies on Glutaraldehyde Crosslinked Chitosan Hydrogel Properties for Drug Delivery Systems. International Journal of Polymeric Materials and Polymeric Biomaterials, 62 (11), 605-611.

[31] Agnihotri, S. A., Aminabhavi, T. M. 2004. Controlled Release of Clozapine through Chitosan Microparticles Prepared by A Novel Method. Journal of Controlled Release, 96 (2), 245-259.

[32] Denkbaş, E. B., Seyyal, M., Pişkin, E. 2000. Implantable 5-fluorouracil Loaded Chitosan Scaffolds Prepared by Wet Spinning. Journal of Membrane Science, 172 (1-2), 33-38.

[33] Kulkarni, V. H., Kulkarni, P. V., Keshavayya, J. 2007. Glutaraldehyde-Crosslinked Chitosan Beads for Controlled Release of Diclofenac Sodium. Journal of Applied Polymer Science, 103 (1), 211-217.

[34] Wang, D. S., Li, J. G., Li, H. P., Tang, F. Q. 2009. Preparation and Drug Releasing Property of Magnetic Chitosan-5-fluorouracil Nanoparticles. Transactions of Nonferrous Metals Society of China, 19 (5), 1232-1236.

[35] Gupta, K. C., Kumar, M. N. V. R. 2000. Drug Release Behavior of Beads and Microgranules of Chitosan. Biomaterials, 21 (11), 1115-1119.

[36] Shu, X. Z., Zhu, K. J., Song, W. 2001. Novel pHSensitive Citrate Cross-linked Chitosan Film for Drug Controlled Release. International Journal of Pharmaceutics, 212 (1), 19-28.

[37] Shu, X. Z., Zhu, K. J. 2002. Controlled Drug Release Properties of Ionically Cross-linked Chitosan Beads: The Influence of Anion Structure. International Journal of Pharmaceutics, 233 (1-2), 217-225.

[38] Hejazi, R., Amiji, M. 2002. Stomach-Specific AntiH. pylori Therapy. I: Preparation and Characterization of Tetracyline-Loaded Chitosan Microspheres. International Journal of Pharmaceutics, 235 (1-2), 87-94.

[39] Kasaai, M. R. 2008. Calculation of Viscometric Constants, Hydrodynamic Volume, PolymerSolvent Interaction Parameter, and Expansion Factor for Three Polysaccharides with Different Chain Conformations. Carbohydrate Research, 343 (13), 2266-2277.

[40] Baskar, D., Kumar, S. T. S. 2009. Effect of Deacetylation Time on The Preparation, Properties and Swelling Behavior of Chitosan Films. Carbohydrate Polymers, 78 (4), 767-772. 
[41] Perrin, D. D., Dempsey, B., 1974. Buffers for $p H$ and Metal Ion Control, Ch. 5, Chapman and Hall, London.

[42] Quijada-Garrido, I., Iglesias-Gonzalez, V., MazonArechederra, J. M., Barrales-Rienda, J. M. 2007. The Role Played by The Interactions of Small Molecules with Chitosan and Their Transition Temperatures. Glass-Forming Liquids: 1, 2, 3propantriol (glycerol). Carbohydrate Polymers, 68 (1), 173-186.

[43] Wang, N., Chen, Y., Kim, J. 2007. Electroactive Paper Actuator Made with Chitosan-Cellulose Films: Effect of Acetic Acid. Macromolecular Materials and Engineering, 292 (6), 748-753.

[44] Hemant, K. S. Y., Shivakumar, H. G. 2010. Development of Chitosan Acetate Films for Transdermal Delivery of Propranolol Hydrochloride. Tropical Journal of Pharmaceutical Research, 9 (2), 197-203.

[45] Milosavljevic, N. B., Kljajevic, L. M., Popovic, I. G., Filipovic, J. M., Kalagasidis Krusic, M. T. 2010. Chitosan, Itaconic Acid and Poly (Vinyl Alcohol) Hybrid Polymer Networks of High Degree of Swelling and Good Mechanical Strength. Polymer International, 59 (5), 686-694.

[46] Olukman, M., Sanll, O., Solak, E. K. 2012. Release of Anticancer Drug 5-Fluorouracil from Different Ionically Crosslinked Alginate Beads. Journal of Biomaterials and Nanobiotechnology, 3, 469479.

[47] Mandal, S., Basu, S. K., Sa, B. 2010. Ca ${ }^{2+}$ Ion Crosslinked Interpenetrating Network Matrix Tablets of Polyacrylamide-grafted-Sodium Alginate and Sodium Alginate for Sustained Release of Diltiazem Hydrochloride. Carbohydrate Polymers, 82 (3), 867-873.

[48] Cervera, M. F., Heinämäki, J., Krogars, K., Jörgensen, A. C., Karjalainen, M., Colarte, A. I., Yliruusi, J. 2004. Solid-State and Mechanical Properties of Aqueous Chitosan-Amylose Starch Films Plasticized with Polyols. AAPS PharmSciTech, 5, 1-6.

[49] Dhanikula, A. B., Panchagnula, R. 2004. Development and Characterization of Biodegradable Chitosan Films for Local Delivery of Paclitaxel. The AAPS Journal, 6, 88-99.

[50] Mi, F. L., Sung, H. W., Shyu, S. S. 2001. Release of Indomethacin from A Novel Chitosan Microsphere Prepared by A Naturally Occurring Crosslinker: Examination of Crosslinking and Polycation-Anionic Drug Interaction. Journal of Applied Polymer Science, 81, 1700-1711.

[51] Nagarwal, R. C., Singh, P. N., Kant, S., Maiti, P., Pandit, J. K. 2011. Chitosan Nanoparticles of 5fluorouracil for Pphthalmic Delivery:
Characterization, In-vitro and In-vivo Study. Chem. Pharm. Bull., 59 (2), 272-278. 